\title{
A Case-Control Study Evaluating the Relationship Between Thimerosal-Containing Haemophilus influenzae Type b Vaccine Administration and the Risk for a Pervasive Developmental Disorder Diagnosis in the United States
}

\author{
David A. Geier • Janet K. Kern • Paul G. King • \\ Lisa K. Sykes • Mark R. Geier \\ Received: 3 October 2014 / Accepted: 30 October 2014 / Published online: 11 November 2014 \\ (C) The Author(s) 2014. This article is published with open access at Springerlink.com
}

\begin{abstract}
Thimerosal is an organic mercury ( $\mathrm{Hg}$ )-containing compound ( $49.55 \% \mathrm{Hg}$ by weight) historically added to many multi-dose vials of vaccine as a preservative. A hypothesis testing case-control study evaluated automated medical records in the Vaccine Safety Datalink (VSD) for organic Hg exposure from Thimerosal in Haemophilus influenzae type $\mathrm{b}$ (Hib)-containing vaccines administered at specific times within the first 15 months of life among subjects diagnosed with pervasive developmental disorder (PDD) $(n=534)$ in comparison to controls. The generally accepted biologically nonplausible linkage between Thimerosal exposure and subsequent diagnosis of febrile seizure $(n=5886)$ was examined as a control outcome. Cases diagnosed with PDD received significantly more organic $\mathrm{Hg}$ within the first 6 months of life (odds ratio $(\mathrm{OR})=1.97, p<0.001$ ) and first 15 months of life $(\mathrm{OR}=3.94, p<0.0001)$ than controls, whereas cases diagnosed with febrile seizure were no more likely than controls to have received increased organic $\mathrm{Hg}$. On a per microgram of organic $\mathrm{Hg}$ basis, cases diagnosed with a PDD in comparison to controls were at significantly greater odds $(\mathrm{OR}=1.0197$, $p<0.0001$ ) of receiving increasing organic $\mathrm{Hg}$ exposure within the first 15 months of life, whereas cases diagnosed febrile seizure were no more likely than controls $(\mathrm{OR}=0.999$, $p>0.20$ ) to have received increasing organic $\mathrm{Hg}$ exposure within the first 15 months of life. Routine childhood
\end{abstract}

\author{
D. A. Geier · J. K. Kern • M. R. Geier $(\bowtie)$ \\ The Institute of Chronic Illnesses, Inc, 14 Redgate Ct, Silver Spring, \\ MD 20905, USA \\ e-mail: mgeier@comcast.net \\ J. K. Kern \\ Department of Psychiatry, University of Texas Southwestern Medical \\ Center at Dallas, Dallas, TX, USA \\ P. G. King $\cdot$ L. K. Sykes \\ CoMeD, Inc, Silver Spring, MD, USA
}

vaccination is an important public health tool to reduce the morbidity and mortality associated with infectious diseases, but the present study provides new epidemiological evidence of a significant relationship between increasing organic $\mathrm{Hg}$ exposure from Thimerosal-containing vaccines and the subsequent risk of PDD diagnosis in males and females.

Keywords Autism · Ethylmercury · Merthiolate ·

Thimerosal $\cdot$ Thiomersal $\cdot$ Vaccine

\section{Introduction}

Thimerosal is an organic mercury ( $\mathrm{Hg}$ )-containing compound (49.55\% $\mathrm{Hg}$ by weight) historically added to many multidose vials of vaccine as a preservative since the 1930s [1]. Thimerosal is initially metabolized into ethyl-Hg compounds and thiosalicylate and rapidly binds onto thiol groups found on many proteins in human blood [2]. It is then actively transported across the blood brain barrier, including by the L-type neutral amino acid carrier transport (LAT) system, into human neuronal cells [3, 4], where it significantly accumulates and persists for many months following exposure and alters numbers of neurons in the dentate gyrus of the hippocampus and thalamus $[5,6]$.

In 2008, an ecological birth cohort assessment of Thimerosal exposure in infants and neurodevelopment disorders within the computerized medical records of the Vaccine Safety Datalink (VSD) database was undertaken [7]. A total of 278,624 subjects were examined in birth cohorts from 19901996 that had received their first oral polio vaccination by 3 months of age in the VSD. The birth cohort prevalence rate of the medically diagnosed pervasive developmental disorders (PDDs) of autism and autism spectrum disorder (ASD) was 
calculated. Exposures to organic $\mathrm{Hg}$ from all Thimerosalcontaining vaccines were calculated by birth cohort for specific exposure windows from birth to 7 months and birth to 13 months of age. Poisson regression analysis was used to model the association between the prevalence of outcomes and organic $\mathrm{Hg}$ doses from Thimerosal-containing vaccines. That study found consistent significantly increased rate ratios for diagnosed autism and ASD with increasing organic $\mathrm{Hg}$ exposure from Thimerosal-containing vaccines from birth to 7 months and birth to 13 months of age.

Subsequently, in 2013, a case-control assessment of organic $\mathrm{Hg}$ from Thimerosal-containing hepatitis B vaccination in infants who were diagnosed autism in the computerized medical records within the VSD database was undertaken [8]. Subjects diagnosed with autism in comparison to controls were significantly more likely to have received increased organic $\mathrm{Hg}$ exposure from Thimerosal-containing hepatitis B vaccines within the first month of life, the first 2 months of life, and the first 6 months of life.

Finally, and most recently, a case-control study was undertaken to evaluate the potential dose-response relationship between organic $\mathrm{Hg}$ exposure from Thimerosal-containing hepatitis $\mathrm{B}$ vaccines administered within the first 6 months of life and the risk of diagnosed PDD [9]. On a per microgram $(\mu \mathrm{g})$ of organic $\mathrm{Hg}$ basis, cases diagnosed with a PDD were significantly more likely than controls to have received increased organic $\mathrm{Hg}$ from Thimerosal-containing hepatitis B vaccines administered within the first 6 months of life.

The purpose of the present study was to examine the consistency and extend the previously mentioned studies in the VSD database by undertaking a case-control study to examine organic $\mathrm{Hg}$ exposure from the administration of Thimerosal in Haemophilus influenzae type $\mathrm{b}$ (Hib)-containing vaccines at specific times within the first 15 months of life among subjects diagnosed with a PDD in comparison to controls.

\section{Methods}

The study protocol employed was approved by the US Centers for Disease Control and Prevention (CDC), the Institutional Review Board (IRB) of Kaiser Permanente North-West (KPNW), and the IRB of Kaiser Permanente Northern California (KPNC). The data were analyzed at the secure Research Data Center of the National Center for Health Statistics in Hyattsville, MD. The views expressed in this study do not necessarily reflect those of the CDC or those of Kaiser Permanente.

Determining the Population at Risk

A cohort of over 1.95 million children enrolled in the VSD project (updated through the end of 2000) from KPNW,
Kaiser Permanente Colorado (KPC), and KPNC were examined using $\mathrm{SAS}^{\circledR}$ software. The VSD project was created in 1991 by the National Immunization Program (NIP) of the CDC [10-12]. The project links medical event information, specific vaccine history, and selected demographic information from the computerized databases of several Health Maintenance Organizations (HMOs). The cohort examined was comprised of individuals with non-missing date of birth and non-missing gender, who were continuously HMO enrolled from their date of birth.

\section{Determining Cases}

The outcome files (inpatient and outpatient diagnoses) from this population were then reviewed to find the first instance of International Classification of Disease, 9th revision (ICD-9) diagnosed PDD (ICD-9 code: 299.xx). If there were multiple instances of the same diagnosis in a child, only the first instance was counted. All subjects diagnosed with PDD had to be continuously HMO enrolled from birth until their initial PDD diagnosis. In addition, only subjects diagnosed with a PDD following the administration of all the vaccines under study were included in the present analyses as cases. A total of 534 cases diagnosed with PDD (males $=432$, females $=102$, male/female ratio $=4.2: 1$ ) born between 1991 and 2000 were identified. These subjects diagnosed with PDD were evaluated to determine their age of initial diagnosis of PDD (mean \pm standard deviation $=4.1 \pm 1.56$ years old).

In addition, the generally accepted biologically nonplausible linkage between Thimerosal exposure and subsequent diagnosis of febrile seizure was examined as a control outcome. The outcome files (inpatient and outpatient diagnoses) from this population were reviewed to find the first instance of febrile seizures for each subject defined as 780.3 by ICD-9 coding. If there were multiple instances of the same diagnosis in a subject, only the first instance was counted. In addition, only subjects diagnosed with febrile seizures following the administration of all the vaccines under study were included in the present analyses as cases. A total of 5886 cases diagnosed with febrile seizures (males $=3305$, females $=2581$, male/female ratio=1.3:1) born between 1991 and 2000 were identified. These subjects diagnosed with febrile seizures were evaluated to determine their age of initial diagnosis of febrile seizures (mean \pm standard deviation $=1.54 \pm 1.3$ years old).

\section{Determining Controls}

In order to identify controls without a PDD diagnosis who would have had only a minimal chance of receiving such a diagnosis, controls had to have been continuously enrolled from birth for at least 7.22 years (mean age of initial diagnosis of PDD $+2 \times$ standard deviation of mean age of initial diagnosis of PDD). Applying this follow-up criterion yielded a total 
of 25,632 controls without a PDD diagnosis (males $=13,110$, females $=12,522$, male/female ratio $=1.05$ ) born between 1991 and 1993.

In order to identify controls without a febrile seizure diagnosis who would have had only a minimal chance of receiving such a diagnosis, controls had to have been continuously enrolled from birth for at least 4.14 years (mean age of initial diagnosis of febrile seizure $+2 \times$ standard deviation of mean age of initial diagnosis of febrile seizure). Applying this follow-up criterion yielded a total of 85,111 controls without febrile seizure diagnosis (males $=43,615$, females $=41,496$, male/female ratio=1.05) born between 1991 and 1996.

\section{Thimerosal in Hib-Containing Vaccine Exposure}

The vaccine file for cases and controls was then reviewed to determine the exact dates of Hib-containing vaccine administration. Overall, among the cases and controls, $\mathrm{Hg}$ exposure was assigned as follows: $25-\mu \mathrm{g}$ organic $\mathrm{Hg}$ per dose for whole-cell diphtheria-tetanus-pertussis (DTwP)-Hib vaccine; 25- $\mu \mathrm{g}$ organic $\mathrm{Hg}$ per dose for acellular diphtheria-tetanuspertussis (DTaP)-Hib vaccine; $25-\mu \mathrm{g}$ organic $\mathrm{Hg}$ per dose for Hib vaccine manufactured by Lederle, Praxis Biologics, Wyeth-Ayerst, or Aventis Pasteur, Inc.; 0- $\mu$ g organic Hg per dose for Hib vaccine manufactured by Merck and Company, Inc. or GlaxoSmithKline; $0-\mu \mathrm{g}$ organic $\mathrm{Hg}$ per dose for Hib-hepatitis $\mathrm{B}$ vaccine; and $0-\mu \mathrm{g}$ organic $\mathrm{Hg}$ per dose for those not receiving any type of Hib-containing vaccine. The Thimerosal content for each of the aforementioned vaccines was determined from the official report by the Committee on Infectious Diseases and Committee on Environmental Health of the American Academy of Pediatrics [13].

\section{Statistical Analyses}

The Fisher's exact test statistic and logistic regression statistic from StatsDirect (Version 2.8.0) were utilized for statistical analyses, and a two-sided $p$ value $<0.05$ was considered statistically significant. In the first case-control experimental group (experiment I), the data was examined to determine the frequency of exposure to 50- $\mathrm{g}$ organic $\mathrm{Hg}$ from Thimerosal in Hib-containing vaccines in the first 4 months of life in comparison to the frequency to $25-\mu \mathrm{g}$ organic $\mathrm{Hg}$ from Thimerosal in Hib-containing vaccines in the first 4 months of life among cases diagnosed with PDD and controls using the Fisher's exact test statistic. In the second case-control experimental group (experiment II), the data was examined to determine the frequency receiving $75-\mu \mathrm{g}$ organic $\mathrm{Hg}$ Thimerosal in Hib-containing vaccines within the first 6 months of life in comparison to the frequency receiving $25-\mu \mathrm{g}$ organic $\mathrm{Hg}$ from Thimerosal in Hib-containing vaccines in the first 6 months of life among cases and controls using the Fisher's exact test statistic. In the third case-control experimental group (experiment III), the data was examined to determine the frequency of receiving 100- $\mu$ g organic $\mathrm{Hg}$ Thimerosal Hibcontaining vaccines within the first 15 months of life in comparison to the frequency of receiving $25-\mu \mathrm{g}$ organic $\mathrm{Hg}$ in the first 15 months of life from Thimerosal Hib-containing vaccines among cases and controls using the Fisher's exact test statistic. The aforementioned experiments were repeated when separating the data so that male cases diagnosed with PDD were compared to male controls (experiments IV-VI) and female cases diagnosed with PDD were compared to female controls (experiments VII-IX). In addition, the aforementioned experiments were repeated for the control outcome of febrile seizure for the diagnosis among cases in comparison to controls (experiments X-XII) and by comparing cases diagnosed with PDD to controls with a reduced length of follow-up (4.11 years in comparison to 7.22 years) (experiments XIII-XV). Finally, the logistic regression statistics were utilized to determine, among cases diagnosed with PDD in comparison to controls and among cases diagnosed with febrile seizures in comparison to controls, the frequency of receiving increasing doses of organic $\mathrm{Hg}$ from Thimerosal in Hib-containing vaccines administered within the first 15 months of life.

\section{Results}

Table 1 displays the relationship between cases diagnosed with PDD and controls being administered increasing doses of organic $\mathrm{Hg}$ from Thimerosal in Hib-containing vaccines at several specific points within the first 15 months of life. Overall, it was observed that cases diagnosed with PDD were significantly more likely to receive $75-\mu \mathrm{g}$ organic $\mathrm{Hg}$ exposure from Thimerosal in Hib-containing vaccines compared to 25- $\mu$ g organic $\mathrm{Hg}$ exposure from Thimerosal in Hibcontaining vaccines administered within the first 6 months of life (odds ratio $=1.97, p<0.001$ ) and significantly more likely to receive $100-\mu \mathrm{g}$ organic $\mathrm{Hg}$ exposure from Thimerosal in Hib-containing vaccines in compared to $25-\mu$ g organic $\mathrm{Hg}$ exposure from Thimerosal in Hib-containing vaccines administered within the first 15 months of life (odds ratio= $3.94, p<0.0001)$ than controls.

Tables 2 and 3, respectively, display the relationship between male cases diagnosed with PDD and male controls and female cases diagnosed with PDD and female controls being administered increasing doses of organic $\mathrm{Hg}$ exposure from Thimerosal in Hib-containing vaccines at several specific points within the first 15 months of life. Male cases diagnosed with PDD were significantly more likely to receive $75-\mu \mathrm{g}$ organic $\mathrm{Hg}$ exposure from Thimerosal in Hib-containing vaccines in comparison to $25-\mu \mathrm{g}$ organic $\mathrm{Hg}$ exposure from Thimerosal in Hib-containing vaccines administered within 
Table 1 A summary of organic $\mathrm{Hg}$ exposure from Thimerosal in Hib-containing vaccines among cases diagnosed with pervasive developmental disorders in comparison to controls within the VSD database

${ }^{1}$ Controls were enrolled from birth until at least 7.22 years old without a pervasive developmental disorder diagnosis

Table 2 A summary of organic $\mathrm{Hg}$ exposure from Thimerosal in Hib-containing vaccines among male cases diagnosed with pervasive developmental disorders in comparison to male controls within the VSD database

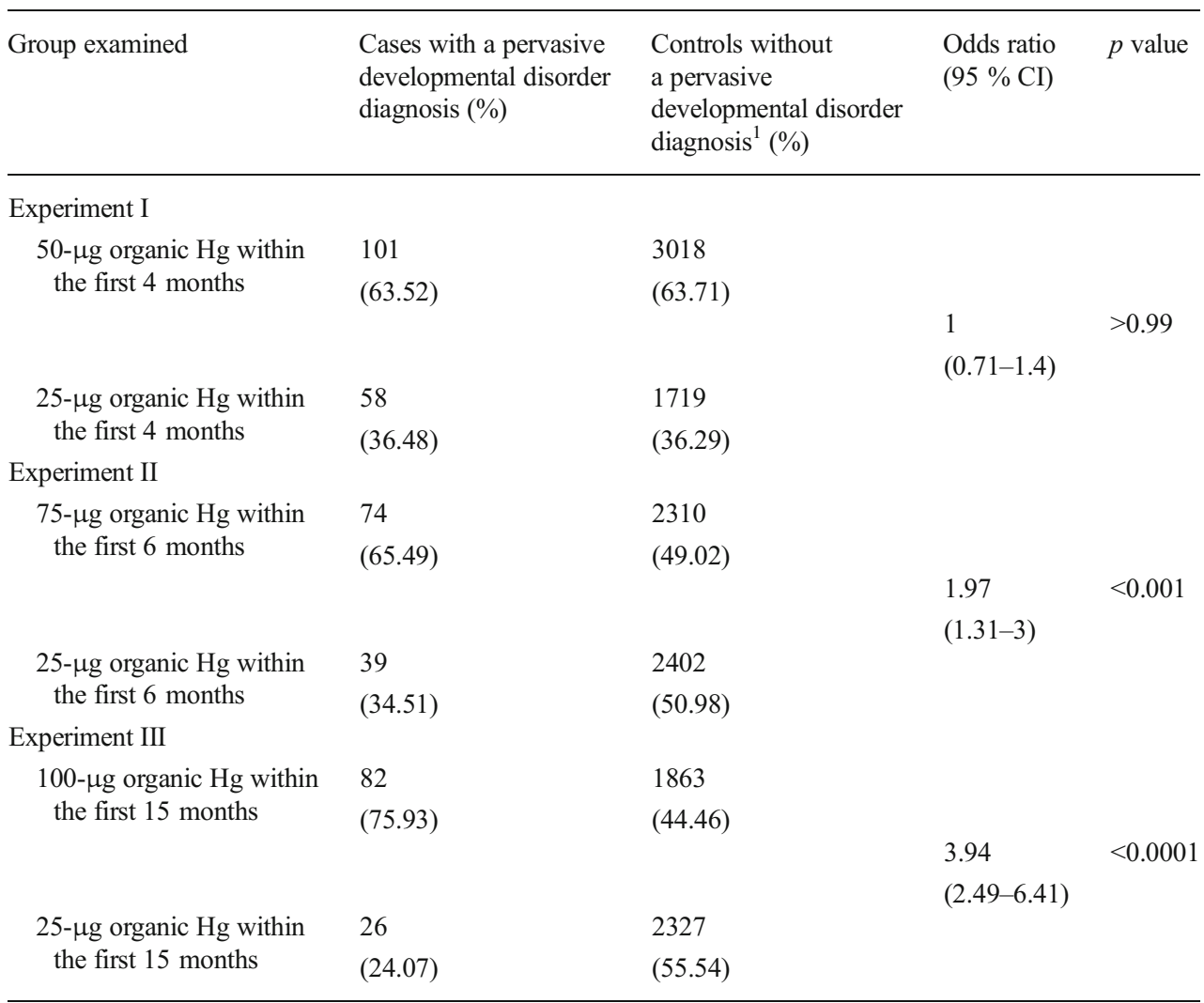

\begin{tabular}{|c|c|c|c|c|}
\hline Group examined & $\begin{array}{l}\text { Male cases with a } \\
\text { pervasive } \\
\text { developmental } \\
\text { disorder diagnosis }(\%)\end{array}$ & $\begin{array}{l}\text { Male controls without } \\
\text { a pervasive } \\
\text { developmental } \\
\text { disorder diagnosis }^{1}(\%)\end{array}$ & $\begin{array}{l}\text { Odds ratio } \\
(95 \% \mathrm{CI})\end{array}$ & $p$ value \\
\hline \multicolumn{5}{|l|}{ Experiment IV } \\
\hline $\begin{array}{l}50-\mu \mathrm{g} \text { organic } \mathrm{Hg} \text { within } \\
\text { the first } 4 \text { months }\end{array}$ & $\begin{array}{l}82 \\
(63.08)\end{array}$ & $\begin{array}{l}1584 \\
(63.9)\end{array}$ & & \\
\hline & & & $\begin{array}{l}0.96 \\
(0.66-1.42)\end{array}$ & $>0.80$ \\
\hline $\begin{array}{l}25-\mu g \text { organic } \mathrm{Hg} \text { within } \\
\text { the first } 4 \text { months }\end{array}$ & $\begin{array}{l}48 \\
(36.92)\end{array}$ & $\begin{array}{l}895 \\
(36.10)\end{array}$ & & \\
\hline \multicolumn{5}{|l|}{ Experiment V } \\
\hline $\begin{array}{l}\text { 75- } \mu \mathrm{g} \text { organic } \mathrm{Hg} \text { within } \\
\text { the first } 6 \text { months }\end{array}$ & $\begin{array}{l}60 \\
(68.18)\end{array}$ & $\begin{array}{l}1175 \\
(48.33)\end{array}$ & & \\
\hline & & & $\begin{array}{l}2.29 \\
(1.43-3.75)\end{array}$ & $<0.0005$ \\
\hline $\begin{array}{l}25-\mu \mathrm{g} \text { organic } \mathrm{Hg} \text { within } \\
\text { the first } 6 \text { months }\end{array}$ & $\begin{array}{l}28 \\
(31.82)\end{array}$ & $\begin{array}{l}1256 \\
(51.67)\end{array}$ & & \\
\hline \multicolumn{5}{|l|}{ Experiment VI } \\
\hline $\begin{array}{l}100-\mu \mathrm{g} \text { organic } \mathrm{Hg} \text { within } \\
\text { the first } 15 \text { months }\end{array}$ & $\begin{array}{l}63 \\
(76.83)\end{array}$ & $\begin{array}{l}981 \\
(45.44)\end{array}$ & & \\
\hline & & & $\begin{array}{l}3.98 \\
(2.33-7.09)\end{array}$ & $<0.0001$ \\
\hline $\begin{array}{l}25-\mu g \text { organic } \mathrm{Hg} \text { within } \\
\text { the first } 15 \text { months }\end{array}$ & $\begin{array}{l}19 \\
(23.17)\end{array}$ & $\begin{array}{l}1178 \\
(54.56)\end{array}$ & & \\
\hline
\end{tabular}

${ }^{1}$ Controls were enrolled from birth until at least 7.22 years old without a pervasive developmental disorder diagnosis 
Table 3 A summary of organic mercury exposure from Thimerosal in Hib-containing vaccines among female cases diagnosed with pervasive developmental disorders in comparison to female controls within the VSD database

\begin{tabular}{|c|c|c|c|c|}
\hline Group examined & $\begin{array}{l}\text { Female cases with } \\
\text { a pervasive } \\
\text { developmental } \\
\text { disorder diagnosis (\%) }\end{array}$ & $\begin{array}{l}\text { Female controls } \\
\text { without a pervasive } \\
\text { developmental } \\
\text { disorder diagnosis }^{1}(\%)\end{array}$ & $\begin{array}{l}\text { Odds ratio } \\
(95 \% \mathrm{CI})\end{array}$ & $p$ value \\
\hline \multicolumn{5}{|l|}{ Experiment VII } \\
\hline \multirow[t]{2}{*}{$\begin{array}{l}50-\mu \mathrm{g} \text { organic } \mathrm{Hg} \text { within } \\
\text { the first } 4 \text { months }\end{array}$} & $\begin{array}{l}19 \\
(65.52)\end{array}$ & $\begin{array}{l}1434 \\
(63.51)\end{array}$ & \multirow{3}{*}{$\begin{array}{l}1.09 \\
(0.48-2.64)\end{array}$} & \multirow{3}{*}{$>0.99$} \\
\hline & & & & \\
\hline $\begin{array}{l}25-\mu g \text { organic } \mathrm{Hg} \text { within } \\
\text { the first } 4 \text { months }\end{array}$ & $\begin{array}{l}10 \\
(34.48)\end{array}$ & $\begin{array}{l}824 \\
(36.49)\end{array}$ & & \\
\hline \multicolumn{5}{|l|}{ Experiment VIII } \\
\hline \multirow[t]{2}{*}{$\begin{array}{l}\text { 75- } \mu \mathrm{g} \text { organic } \mathrm{Hg} \text { within } \\
\text { the first } 6 \text { months }\end{array}$} & $\begin{array}{l}14 \\
(56)\end{array}$ & $\begin{array}{l}1135 \\
(49.76)\end{array}$ & \multirow{3}{*}{$\begin{array}{l}1.29 \\
(0.54-3.14)\end{array}$} & \multirow{3}{*}{$>0.50$} \\
\hline & & & & \\
\hline $\begin{array}{l}25-\mu \mathrm{g} \text { organic } \mathrm{Hg} \text { within } \\
\text { the first } 6 \text { months }\end{array}$ & $\begin{array}{l}11 \\
(44)\end{array}$ & $\begin{array}{l}1146 \\
(50.24)\end{array}$ & & \\
\hline \multicolumn{5}{|l|}{ Experiment IX } \\
\hline \multirow[t]{2}{*}{$\begin{array}{l}100-\mu \mathrm{g} \text { organic } \mathrm{Hg} \text { within } \\
\text { the first } 15 \text { months }\end{array}$} & $\begin{array}{l}19 \\
(73.08)\end{array}$ & $\begin{array}{l}882 \\
(43.43)\end{array}$ & \multirow{3}{*}{$\begin{array}{l}3.54 \\
(1.41-9.99)\end{array}$} & \multirow{3}{*}{$<0.005$} \\
\hline & & & & \\
\hline $\begin{array}{l}25-\mu g \text { organic } \mathrm{Hg} \text { within } \\
\text { the first } 15 \text { months }\end{array}$ & $\begin{array}{l}7 \\
(26.92)\end{array}$ & $\begin{array}{l}1149 \\
(56.57)\end{array}$ & & \\
\hline
\end{tabular}

${ }^{1}$ Controls were enrolled from birth until at least 7.22 years old without a pervasive developmental disorder diagnosis
15 months of life. On a per microgram of organic $\mathrm{Hg}$ basis, cases diagnosed with a PDD in comparison to controls were at significantly greater odds (odds ratio $=1.0197, p<0.0001$ ) of receiving increasing organic $\mathrm{Hg}$ exposure from Thimerosal in Hib-containing vaccines. As a consequence for the maximum dose of an additional 75- $\mathrm{gg}$ organic $\mathrm{Hg}$ exposure from Thimerosal in Hib-containing vaccines administered within the first 15 months of life, cases diagnosed with PDD in comparison to controls were 2.478 -fold significantly more likely to receive $100-\mu \mathrm{g}$ organic $\mathrm{Hg}$ from Thimerosal in Hibcontaining vaccines in comparison to $25-\mu \mathrm{g}$ organic $\mathrm{Hg}$ exposure from Thimerosal in Hib-containing vaccines administered within the first 15 months of life. By contrast, on a per microgram of organic $\mathrm{Hg}$ basis, cases diagnosed with febrile seizure in comparison to controls were no more likely (odds ratio $=0.999, p>0.20$ ) of receiving increasing organic $\mathrm{Hg}$ exposure from Thimerosal in Hib-containing vaccines.

Table 6 summarizes the discrete point odds ratio estimates and logistic regression odds ratio estimates for an additional 25-, 50-, or 75- $\mu$ g organic $\mathrm{Hg}$ from Thimerosal in Hib-containing vaccines administered within the first 15 months of life among cases diagnosed with a PDD in comparison to controls. The discrete point odds ratio estimates and logistic regression odds ratio estimates were of similar order-of-magnitude for increasing exposure to organic $\mathrm{Hg}$ for cases diagnosed with a PDD in comparison to controls. 
Table 4 A summary of organic $\mathrm{Hg}$ exposure from Thimerosal in Hib-containing vaccines among cases diagnosed with a febrile seizure in comparison to controls within the VSD database

${ }^{1}$ Controls were enrolled from birth until at least 4.14 years old without a febrile seizure diagnosis

\begin{tabular}{|c|c|c|c|c|}
\hline Group examined & $\begin{array}{l}\text { Cases with a febrile } \\
\text { seizure diagnosis (\%) }\end{array}$ & $\begin{array}{l}\text { Controls without } \\
\mathrm{n} \text { febrile seizure } \\
\text { diagnosis }^{1}(\%)\end{array}$ & $\begin{array}{l}\text { Odds ratio } \\
(95 \% \mathrm{CI})\end{array}$ & $p$ value \\
\hline \multicolumn{5}{|l|}{ Experiment $\mathrm{X}$} \\
\hline $\begin{array}{l}50-\mu \mathrm{g} \text { organic } \mathrm{Hg} \text { within } \\
\text { the first } 4 \text { months }\end{array}$ & $\begin{array}{l}1215 \\
(62.12)\end{array}$ & $\begin{array}{l}17,176 \\
(63.54)\end{array}$ & & \\
\hline $\begin{array}{l}25-\mu \mathrm{g} \text { organic } \mathrm{Hg} \text { within } \\
\text { the first } 4 \text { months }\end{array}$ & $\begin{array}{l}741 \\
(37.88)\end{array}$ & $\begin{array}{l}9857 \\
(36.46)\end{array}$ & $\begin{array}{l}0.94 \\
(0.86-1.03)\end{array}$ & $>0.20$ \\
\hline \multicolumn{5}{|l|}{ Experiment XI } \\
\hline $\begin{array}{l}\text { 75- } \mu \mathrm{g} \text { organic } \mathrm{Hg} \text { within } \\
\text { the first } 6 \text { months }\end{array}$ & $\begin{array}{l}936 \\
(62.61)\end{array}$ & $\begin{array}{l}13,412 \\
(70.5)\end{array}$ & & \\
\hline $\begin{array}{l}25-\mu \mathrm{g} \text { organic } \mathrm{Hg} \text { within } \\
\text { the first } 6 \text { months }\end{array}$ & $\begin{array}{l}559 \\
(37.39)\end{array}$ & $\begin{array}{l}5613 \\
(29.50)\end{array}$ & $\begin{array}{l}0.70 \\
(0.63-0.78)\end{array}$ & $<0.0001$ \\
\hline \multicolumn{5}{|l|}{ Experiment XII } \\
\hline $\begin{array}{l}100-\mu \mathrm{g} \text { organic } \mathrm{Hg} \text { within } \\
\text { the first } 15 \text { months }\end{array}$ & $\begin{array}{l}1224 \\
(78.82)\end{array}$ & $\begin{array}{l}14,402 \\
(78.47)\end{array}$ & & \\
\hline & & & $\begin{array}{l}1.02 \\
(0.9-1.16)\end{array}$ & $>0.75$ \\
\hline $\begin{array}{l}25-\mu \mathrm{g} \text { organic } \mathrm{Hg} \text { within } \\
\text { the first } 15 \text { months }\end{array}$ & $\begin{array}{l}329 \\
(21.18)\end{array}$ & $\begin{array}{l}3952 \\
(21.53)\end{array}$ & & \\
\hline
\end{tabular}

\section{Discussion}

As previously published by investigators from the CDC and the US Food and Drug Administration (FDA), products, such as vaccines, which are intended for healthy people, must be held to a high standard of safety assurance [14]. However, these previous investigators described that the study of vaccine risks is more complex than for therapeutic products because the exposure is nearly universal for many vaccines, ensuring the chance occurrence of many subsequent temporally associated adverse outcomes after the administration of vaccines. As a result, these investigators described using the VSD, a consortium of HMOs, to more rigorously evaluate post-vaccination associated risks (hypothesis testing).
Table 5 A summary of the potential dose-dependent relationship between exposure to organic $\mathrm{Hg}$ from Thimerosal in Hib-containing vaccines administered within the first 15 months of life among cases in comparison to controls

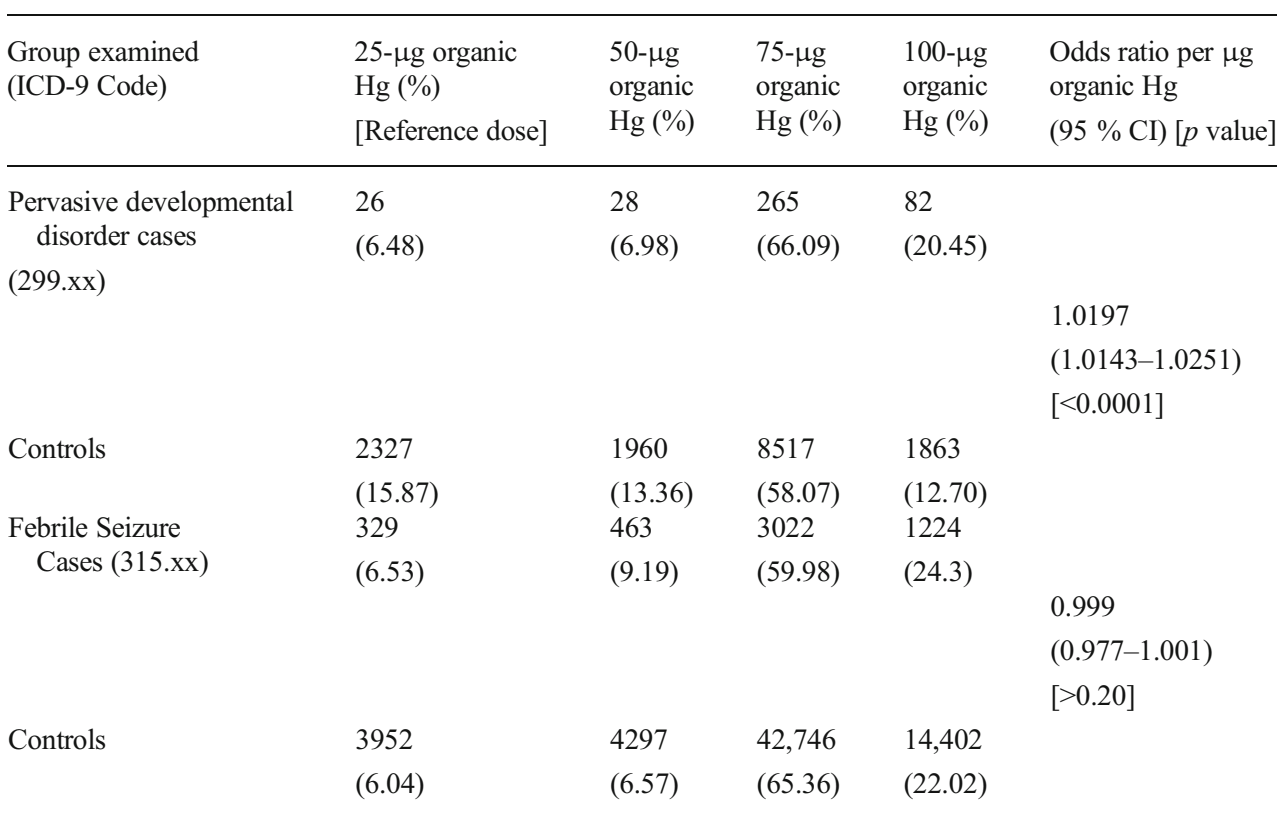


Table 6 A summary of exposure to organic $\mathrm{Hg}$ from Thimerosal in Hib-containing vaccines administered within the first 15 months of life for the cases diagnosed with PDD and controls by both the discrete point odds ratio estimates and the logistic regression odds ratio estimates ${ }^{1}$

\begin{tabular}{|c|c|c|c|c|}
\hline \multirow[b]{2}{*}{$\begin{array}{l}\text { Group examined } \\
\text { (ICD-9 Code) }\end{array}$} & \multirow[b]{2}{*}{ Statistical approach used } & \multicolumn{3}{|c|}{ Organic $\mathrm{Hg}$ exposure level above the reference dose ${ }^{1}$} \\
\hline & & $25-\mu \mathrm{g}$ organic $\mathrm{Hg}(95 \% \mathrm{CI})$ & $50-\mu \mathrm{g}$ organic $\mathrm{Hg}(95 \% \mathrm{CI})$ & $75-\mu g$ organic $\mathrm{Hg}(95 \% \mathrm{CI})$ \\
\hline & Discrete point odds ratio estimates & $\begin{array}{l}1.28 \\
(0.72-2.3)\end{array}$ & $\begin{array}{l}2.8 \\
(1.9-4.4)\end{array}$ & $\begin{array}{l}3.9 \\
(2.5-6.4)\end{array}$ \\
\hline \multicolumn{5}{|c|}{ Pervasive developmental disorder cases (299.xx) } \\
\hline & Logistic regression odds ratio estimates & $\begin{array}{l}1.493 \\
(1.358-1.628)\end{array}$ & $\begin{array}{l}1.985 \\
(1.715-2.255)\end{array}$ & $\begin{array}{l}2.478 \\
(2.073-2.883)\end{array}$ \\
\hline
\end{tabular}

${ }^{1}$ The exposure "reference dose" is $25 \mu \mathrm{g}$ of organic $\mathrm{Hg}$ from Thimerosal in Hib-containing vaccines

The present study revealed cases diagnosed with PDD were overall, among both male and female cases analyzed separately, and on a dose-dependent basis, significantly more likely than controls to receive increased organic $\mathrm{Hg}$ exposure from Thimerosal in Hib-containing vaccines administered at specific intervals within the first 15 months of life. The results of the present study are consistent with and extend the previous ecological birth cohort study [7] and case-control studies [8,9] of the potential relationship between organic $\mathrm{Hg}$ exposure from Thimerosal-containing childhood vaccines and PDD in the VSD database. The size and magnitude of the observed relationship on a per microgram organic $\mathrm{Hg}$ basis are similar to the previously discussed VSD studies and suggest that the phenomena observed in the VSD database is more than mere chance. In addition, the significant association observed between organic $\mathrm{Hg}$ exposure and subsequently diagnosed PDD is consistent with several other studies examining other databases such as the National Health Interview Survey (NHIS) [15] and the Vaccine Adverse Event Reporting System (VAERS) [8, 16].

The results of the present study stand in contrast to six previous epidemiological studies that failed to find a significant relationship between $\mathrm{Hg}$ exposure from Thimerosal-containing childhood vaccines and diagnosed PDD [17-22]. As recently reviewed, the aforementioned studies were found to have significant methodological concerns, and, as a consequence, their potential ability to contribute to understanding the potential relationship between organic $\mathrm{Hg}$ exposure from Thimerosalcontaining childhood vaccines and diagnosed PDD was found to be not interpretable [23].

In further support of the biological plausibility of the phenomena observed in the present study, investigators have examined a number of different lines of scientific inquiry. For example, investigators recently published a critical review on the mechanisms of how limited thiol availability, abnormal sulfation chemistry, and decreased glutathione reserve capacity in children diagnosed with PDD could make them more susceptible to the toxic effects of Thimerosal routinely administered as part of childhood immunization schedules [24]. Another study demonstrated that human neuronal systems exposed to low concentrations of Thimerosal were able to induce cellular damage similar to that observed in the neuropathological studies of subjects diagnosed with a PDD [25]. Finally, several recent studies of Thimerosal exposure in animal model systems resulted in neuropathological and behavioral symptoms similar to those associated with PDD [26-30].

\section{Strengths/Limitations}

In considering the strength of the results observed, the VSD observations made were based upon retrospective assessment of prospectively collected medical records of patients enrolled in various HMOs. As such, the VSD data examined were collected independently of the study design and were, in fact, collected as part of the routine healthcare individuals received as part of the participation with their respective HMOs. Thus, at the times of the collection of these records, the healthcare providers probably were not thinking about the potential association between vaccine exposures and potential subsequent adverse health outcomes.

The study design used to evaluate the potential relationship between exposure and outcome was another significant strength of the present study. Cases examined in the present study had to be enrolled from birth and were required to be continuously enrolled until a medical diagnosis of PDD was made. Moreover, controls had to be enrolled from birth for a sufficient time period to ensure that there was a very small chance that, during additional follow-up, any of the controls would be medically diagnosed with a PDD. As a result, factors associated with enrollment (i.e., adjustment for potential independent variables between cases and controls were not necessary because enrollment was from birth) or healthcareseeking behavior (i.e., adjustment for potential access/ availability of healthcare was continuous among cases and 
controls) were minimized. In addition, cases diagnosed with a PDD were specifically evaluated to ensure that only those cases diagnosed with an PDD following vaccine administration were considered in the present analyses.

An additional strength of the present study is that it was decided, a priori, to ensure adequate amounts of data for our analyses and that the included controls would be HMO enrolled continuously from birth until they were at least the mean age of initial diagnosis of PDD plus twice the standard deviation of the mean age of initial diagnosis of PDD. For cases diagnosed with a PDD, it was possible to mathematically evaluate the mean and standard deviation of age for initial PDD diagnoses within the VSD. From this information, it was possible to estimate how many additional potential diagnoses of PDD were missed. It was decided, a priori, to ensure adequate amounts of data for our analyses and that controls had to be continuously enrolled in the VSD from birth until they were at least 7.22 years old (mean age of initial diagnosis of PDD $+2 \times$ standard deviation of the mean age of initial diagnosis of PDD). Based on the data for age of initial diagnosis for PDD, this was a sufficient period to ensure that, with further follow-up, those controls without PDD would probably not receive a PDD diagnoses in the VSD (mathematically there is a $<2.5 \%$ chance of these individuals being diagnosed with a PDD with additional follow-up time beyond 7.22 years). As shown in Table 7, when the length of follow-up of controls examined was reduced to only the mean age of initial diagnosis of PDD (i.e., cases/controls were followed for same length of time and mathematically there is an about $50 \%$ error), the overall adverse effects observed on a per microgram basis from increasing exposure to organic $\mathrm{Hg}$ exposure from Thimerosal in Hib-containing vaccines completely disappear. Clearly, these analyses establish the importance of following controls in any study of PDDs for a sufficient period to ensure that the risk of a control being subsequently diagnosed with a "case" condition is as small as possible, subject to the limitations of the records that are accessible for study.

A further strength of the present study was the specific methods employed to evaluate differences in cumulative doses of organic $\mathrm{Hg}$ received at specific intervals during the infant period were not the result of small group of children receiving anomalous exposure to vaccines. Instead, the subjects examined were exposed to different levels of organic $\mathrm{Hg}$ based upon differences in the Thimerosal content of licensed Hib vaccines [13] and the recommendations on the ages for the administration of Hib vaccines to children made by the 1991 Advisory Committee on Immunization Practices recommendations [31].

However, the results of the present study may have a number of potential limitations. For example, the results observed may have occurred from unknown biases or cofounders present in the datasets examined. This seems unlikely because the control outcome of febrile seizure (i.e., an outcome that is not biologically plausibly linked to postnatal organic $\mathrm{Hg}$ exposure from Thimerosal-containing vaccines) was examined, using the same methodology employed for
Table 7 A summary of organic $\mathrm{Hg}$ exposure from Thimerosal in Hib-containing vaccines among cases diagnosed with a PDD in comparison to controls with a reduced length of follow-up ${ }^{1}$

\begin{tabular}{|c|c|c|c|c|}
\hline Group examined & $\begin{array}{l}\text { Cases with a pervasive } \\
\text { developmental disorder } \\
\text { diagnosis }(\%)\end{array}$ & $\begin{array}{l}\text { Controls without a } \\
\text { pervasive developmental } \\
\text { disorder diagnosis }(\%)\end{array}$ & $\begin{array}{l}\text { Odds ratio } \\
(95 \% \mathrm{CI})\end{array}$ & $p$ value \\
\hline \multicolumn{5}{|l|}{ Experiment XIII } \\
\hline $\begin{array}{l}50 \mu \mathrm{g} \text { organic } \mathrm{Hg} \text { within } \\
\text { the first } 4 \text { months }\end{array}$ & $\begin{array}{l}101 \\
(63.52)\end{array}$ & $\begin{array}{l}17,938 \\
(63.60)\end{array}$ & & \\
\hline & & & $\begin{array}{l}1 \\
(0.72-1.38)\end{array}$ & $>0.95$ \\
\hline $\begin{array}{l}25-\mu \mathrm{g} \text { organic } \mathrm{Hg} \text { within } \\
\text { the first } 4 \text { months }\end{array}$ & $\begin{array}{l}58 \\
(36.48)\end{array}$ & $\begin{array}{l}10,268 \\
(36.40)\end{array}$ & & \\
\hline \multicolumn{5}{|l|}{ Experiment XIV } \\
\hline $\begin{array}{l}\text { 75- } \mu \text { g organic } \mathrm{Hg} \text { within } \\
\text { the first } 6 \text { months }\end{array}$ & $\begin{array}{l}74 \\
(65.49)\end{array}$ & $\begin{array}{l}14,027 \\
(70.41)\end{array}$ & & \\
\hline & & & $\begin{array}{l}0.8 \\
(0.54-1.18)\end{array}$ & $>0.20$ \\
\hline $\begin{array}{l}\text { 25- } \mu \text { g organic } \mathrm{Hg} \text { within } \\
\text { the first } 6 \text { months }\end{array}$ & $\begin{array}{l}39 \\
(34.51)\end{array}$ & $\begin{array}{l}5896 \\
(29.59)\end{array}$ & & \\
\hline \multicolumn{5}{|l|}{ Experiment XV } \\
\hline $\begin{array}{l}100-\mu \mathrm{g} \text { organic } \mathrm{Hg} \text { within } \\
\text { the first } 15 \text { months }\end{array}$ & $\begin{array}{l}82 \\
(75.93)\end{array}$ & $\begin{array}{l}15,020 \\
(78.41)\end{array}$ & & \\
\hline & & & $\begin{array}{l}0.87 \\
(0.56-1.35)\end{array}$ & $>0.50$ \\
\hline $\begin{array}{l}25-\mu g \text { organic } \mathrm{Hg} \text { within } \\
\text { the first } 15 \text { months }\end{array}$ & $\begin{array}{l}26 \\
(24.07)\end{array}$ & $\begin{array}{l}4135 \\
(21.59)\end{array}$ & & \\
\hline
\end{tabular}

${ }^{1}$ Controls were enrolled from birth until at least 4.11 years old without a pervasive developmental disorder diagnosis 
PDD. As shown in Tables 4 and 5, no similar patterns of significant associations were observed as those that were found for organic $\mathrm{Hg}$ exposure from Thimerosal in Hib-containing vaccines and the subsequent risk of PDD diagnosis.

Another potential limitation of the present study is that the results observed may be the result of statistical chance. However, such a possibility would be unlikely given the limited number of statistical tests performed, the highly significant results observed (most $p$ values observed were $<0.01$ ), and the consistency in the direction and magnitude of the results observed. In addition, it was observed that there were similar order-ofmagnitude odds ratios for increasing organic $\mathrm{Hg}$ exposure among cases diagnosed with a PDD in comparison to controls for discrete point estimates and logistic regression estimates.

Still, other potential limitations of the present study include the possibilities that some of the individuals in VSD examined may have had more subtle neurological dysfunction, which was not brought to the attention of their healthcare providers; healthcare providers may have misdiagnosed some individuals; or some vaccine exposures may not have been appropriately classified. In addition, it is possible that some of the organic $\mathrm{Hg}$ exposures from the Hib-containing vaccines were different than the estimated amount. For example, ActHIB vaccine manufactured by Aventis Pasteur was always Thimerosal free, but it was usually reconstituted with Thimerosal-containing Tripedia, but it is possible that some doses were reconstituted with just plain saline. Similarly, some Hib vaccines by Merck and Company, Inc. may have had 12.5- $\mu$ g organic Hg per dose, and not the assigned $0-\mu \mathrm{g}$ organic $\mathrm{Hg}$ per dose. In addition, it is possible that some very small number of doses of HibTITTER vaccine manufactured by Lederle may have come in singledose vials with $0-\mu g$ organic $\mathrm{Hg}$ per dose, and not the assigned $25-\mu \mathrm{g}$ organic $\mathrm{Hg}$ per dose. These limitations, while possibly present in the data examined in the current study, should not have significantly impacted the results observed because it is unclear how differential application would have occurred to the study cohorts examined based upon the Thimerosal doses that the individuals received. Moreover, misclassification occurring in the data examined would tend to bias any results observed toward the null hypothesis, since such effects would result in individuals being placed in the wrong exposure and/or outcome categories examined, and result in decreased statistical power to determine true potential exposure-outcome relationships.

In addition, another potential limitation of the present study is that exposures to other sources of $\mathrm{Hg}$ were not evaluated. At this time, data analysis restrictions imposed by the CDC prevent us from studying more than one type of vaccine subjects received, despite the fact that it is very likely that the subjects examined incurred other organic $\mathrm{Hg}$ exposures from other Thimerosal-containing childhood vaccines. It is also likely that subjects examined received $\mathrm{Hg}$ exposures from dental amalgams, fish, or other environmental sources. While all these other sources of $\mathrm{Hg}$ may play a significant involvement in the pathogenesis PDD, these unaccounted for $\mathrm{Hg}$ exposures would actually tend to bias the results observed toward the null hypothesis because they potentially would confound the specific exposure classifications of $\mathrm{Hg}$ examined. For example, individuals classified as having lower organic $\mathrm{Hg}$ exposure from Thimerosal-containing vaccines may have actually received high doses of $\mathrm{Hg}$ from other sources, and individuals having higher organic $\mathrm{Hg}$ exposure from Thimerosalcontaining vaccines may have actually received low doses of $\mathrm{Hg}$ from other sources, with the net result tending to minimize the magnitude of the associations observed.

It is also possible that the findings reported may be the result of other components of the vaccines studied, which in isolation or synergistically interacted with the organic $\mathrm{Hg}$ exposures examined in the present study. These possibilities seem remote, since multiple different brands of Hib-containing vaccines were examined (with many different amounts/types of adjuvants and trace constituents), but a significant overall and dose-dependent relationship was observed among cases diagnosed with a PDD in comparison to controls for increasing organic $\mathrm{Hg}$ exposure. Moreover, any effects of other components of vaccines working in isolation or synergistically would tend to bias the results observed toward the null hypothesis because they were not considered in the statistical analyses undertaken.

Additionally, a potential limitation of the present study is there may be differences in the general health status among the subjects examined independent of exposure to organic $\mathrm{Hg}$ from Hib-containing vaccine administration. As described previously by investigators from the $\mathrm{CDC}$ [32], confounding of this sort is a general problem for studies of adverse reactions to prophylactic interventions, as they may be withheld from some individuals precisely because they are already at high risk of the adverse event, and, as a consequence, studies that fail to adequately control for such confounding factors are likely to underestimate the risk of adverse events attributable to vaccination. In order to help minimize that potential effect in our analyses, we utilized a reference group that received $25 \mu \mathrm{g}$ organic $\mathrm{Hg}$ exposure from Hib-containing vaccines in all of our statistical analyses. Despite our attempt to minimize these phenomena in our analyses, we did observe that there was an apparent protective association for increased organic $\mathrm{Hg}$ exposure from Thimerosal in Hibcontaining vaccines for our control outcome of febrile seizure compared to controls. As a consequence, there was a "healthy vaccine" effect in our data. Since this phenomenon is apparent in the data examined, the significantly increased positive dosedependent associations observed for the PDD probably underestimates the true extent of the relationship between organic $\mathrm{Hg}$ exposure from Thimerosal in Hib-containing vaccines and the subsequent PDD outcome studied.

Finally, the current study suffers from the potential limitation that analyses were not conducted to further explore the precise timing and cumulative doses of organic $\mathrm{Hg}$ from all Thimerosal-containing childhood vaccines associated with 
maximum adverse consequences. In future studies, it would be worthwhile to further explore these precise-timing and cumulative-doses phenomena. In addition, it would be valuable to evaluate other neurodevelopmental outcomes, as well as other covariates such as gender, race, birth weight, etc., that may further affect the magnitude of the adverse effects found.

\section{Conclusion}

The present case-control study revealed consistent and significantly increased associations between exposure to organic $\mathrm{Hg}$ from Thimerosal in Hib-containing vaccines administered at specific times within the first 15 months of life among subjects (both male and female) subsequently diagnosed with a PDD in comparison to controls. The results also revealed that, on a dose-dependent basis, subjects diagnosed with a PDD were significantly more likely than controls to have received increased organic $\mathrm{Hg}$ exposure from Thimerosal in Hibcontaining vaccines. The present study is both consistent with and extends previous epidemiological studies in the VSD database and provides compelling new epidemiological evidence supporting a significant relationship between increasing organic Hg exposure from Thimerosal-containing childhood vaccines and the subsequent risk of a PDD.

As previously described, routine childhood vaccination may be an important public health tool to reduce the morbidity and mortality associated with infectious diseases [33]. However, it is also a public health imperative to end the unnecessary addition of organic $\mathrm{Hg}$ to vaccines in the form of Thimerosal used as a preservative or otherwise, based on data showing an association between its administration and the increasing risk for the adverse outcomes studied.

Acknowledgments We wish to thank Dr. Brian Hooker for his computer programming expertise in helping to analyze the VSD database. This study was supported by the non-profit Institute of Chronic Illnesses, Inc. and the non-profit CoMeD, Inc. This study was also supported the Seltz Foundation and the Dwoskin Family Foundation, but they were not involved in the design and conduct of the study, in the collection analysis, in the interpretation of the data, in the preparation, and in the review nor in the approval of the manuscript.

Open Access This article is distributed under the terms of the Creative Commons Attribution License which permits any use, distribution, and reproduction in any medium, provided the original author(s) and the source are credited.

\section{References}

1. Geier DA, Sykes LK, Geier MR (2007) A review of Thimerosal (Merthiolate) and its ethylmercury breakdown product: specific historical considerations regarding safety and effectiveness. J Toxicol Environ Health B Crit Rev 10:575-596
2. Trumpler S, Meermann B, Nowak S, Buscher W, Karst U, Sperling M (2014) In vitro study of Thimerosal reactions in human whole blood and plasma surrogate samples. J Trace Elem Med Biol 28:125130

3. Wehe CA, Pieper I, Holtkamp M, Thyssen GM, Sperling M, Schwerdtle T, Karst U (2014) On-line species-unspecific isotope dilution analysis in the picomolar range reveals the time- and species-depending mercury uptake in human astrocytes. Anal Bioanal Chem 406:1909-1916

4. Zimmermann LT, Santos DB, Naime AA, Leal RM, Dorea JG, Barbosa F Jr, Aschner M, Rocha JB, Farina M (2013) Comparative study on methyl- and ethylmercury-induced toxicity in C6 glioma cells and the potential role of LAT-1 in mediating mercurial-thiol complexes uptake. Neurotoxicology 38:1-8

5. Burbacher TM, Shen DD, Liberato N, Grant KS, Cernichiari E, Clarkson T (2005) Comparison of blood and brain mercury levels in infant monkeys exposed to methylmercury or vaccines containing Thimerosal. Environ Health Perspect 113:1015-1021

6. Burbacher TM, Charleston LB, Charleston J (2014) A comparative study of Thimerosal in vaccines with methylmercury in a nonhuman primate model. Neurotoxicol Teratol 43:91

7. Young HA, Geier DA, Geier MR (2008) Thimerosal exposure in infants and neurodevelopmental disorders: an assessment of computerized medical records in the Vaccine Safety Datalink. J Neurol Sci 271:110-118

8. Geier DA, Hooker BS, Kern JK, King PG, Sykes LK, Geier MR (2013) A two-phase study evaluating the relationship between Thimerosal-containing vaccine administration and the risk for an autism spectrum disorder diagnosis in the United States. Transl Neurodegener 2:25

9. Geier DA, Hooker BS, Kern JK, King PG, Sykes LK, Geier MR (2014) A dose-response relationship between organic mercury exposure from Thimerosal-containing vaccines and neurodevelopmental disorders. Int J Environ Res Public Health 11:9156-9170

10. Chen RT, DeStefano F, Davis RL, Jackson LA, Thompson RS, Mullooly JP, Black SB, Shinefield HR, Vadheim CM, Ward JI, Marcy SM (2000) The Vaccine Safety Datalink: immunization research in health maintenance organizations in the USA. Bull World Health Organ 78:186-194

11. Chen RT, Glasser JW, Rhodes PH, Davis RL, Barlow WE, Thompson RS, Mullooly JP, Black SB, Shinefield HR, Vadheim CM, March SM, Ward JI, Wise RP, Wassilak SG, Hadler SC, The Vaccine Safety Datalink Team (1997) Vaccine Safety Datalink project: a new tool for improving vaccine safety monitoring in the United States. Pediatrics 99:765-773

12. Wassilak SG, Glasser JW, Chen RT, Hadler SC, The Vaccine Safety Datalink Investigators (1995) Utility of large-linked databases in vaccine safety, particularly in distinguishing independent and synergistic effects. Ann N Y Acad Sci 754:377-382

13. Committee on Infectious Diseases and Committee on Environmental Health (1999) Thimerosal in vaccines - an interim report to clinicians. Pediatrics 104:570

14. Ellenberg SS, Braun MM (2002) Monitoring the safety of vaccines: assessing the risks. Drug Saf 25:145-152

15. Gallagher CM, Goodman MS (2010) Hepatitis B vaccination of male neonates and autism diagnosis, NHIS 1997-2002. J Toxicol Environ Health A 73:1665-1677

16. Geier DA, Kern JK, King PG, Sykes LK, Geier MR (2014) The risk of neurodevelopmental disorders following a Thimerosal-preserved DTaP formulation in comparison to its Thimerosal-reduced formulation in the Vaccine Adverse Event Reporting System (VAERS). J Biochem Pharm Res 2:64-73

17. Madsen KM, Lauritsen MB, Pedersen CM, Thorsen P, Plesner AM, Andersen PH, Mortensen PB (2003) Thimerosal and the occurrence of autism: negative ecological evidence from Danish populationbased data. Pediatrics 112:604-606 
18. Stehr-Green P, Tull P, Stellfeld M, Mortenson PB, Simpson D (2003) Autism and Thimerosal-containing vaccines: lack of consistent evidence for an association. Am J Prev Med 25:101-106

19. Hviid A, Stellfeld M, Wohlfahrt J, Melbye M (2003) Association between Thimerosal-containing vaccine and autism. JAMA 290: 1763-1766

20. Andrews N, Miller E, Grant A, Stowe J, Osbrone V, Taylor B (2004) Thimerosal exposure in infants and developmental disorders: a retrospective cohort study in the United Kingdom does not support a causal association. Pediatrics 114:584-591

21. Verstraeten T, Davis RL, DeStefano F, Lieu TA, Rhodes PH, Black SB, Shinefield H, Chen RT, Vaccine Safety Datalink Team (2003) Safety of Thimerosal-containing vaccines: a two-phased study of computerized health maintenance organization databases. Pediatrics 112:1039-1048

22. Price CS, Thompson WW, Goodson B, Weintraub ES, Croen LA, Hinrichsen VL, Marcy M, Robertson A, Eriksen E, Lewis E, Bernal P, Shay D, Davis RL, DeStefano F (2010) Prenatal and infant exposure to Thimerosal from vaccines and immunoglobulins and risk of autism. Pediatrics 126:656-664

23. Hooker B, Kern J, Geier D, Haley B, Sykes L, King P, Geier M (2014) Methodological issues and evidence of malfeasance in research purporting to show Thimerosal in vaccines is safe. Biomed Res Int 2014:247218

24. Kern JK, Haley BE, Geier DA, Sykes LK, King PG, Geier MR (2013) Thimerosal exposure and the role of sulfation chemistry and thiol availability in autism. Int J Environ Res Public Health 10:37713800

25. Geier DA, King PG, Geier MR (2009) Mitochondrial dysfunction, impaired oxidative-reduction activity, degeneration, and death in human neuronal and fetal cells induced by low-level exposure to
Thimerosal and other metal compounds. Toxicol Environ Chem 91: 735-749

26. Li X, Qu F, Xie W, Wang F, Liu H, Song S, Chen T, Zhang Y, Zhe S, Wang Y, Guo C, Tang TS (2014) Transcriptomic analyses of neurotoxic effects in mouse brain after intermittent neonatal administration of Thimerosal. Toxicol Sci 139:452-465

27. Sulkowski ZL, Chen T, Midha S, Zavacki AM, Sajdel-Sulkowska EM (2012) Maternal Thimerosal exposure results in aberrant cerebellar oxidative stress, thyroid hormone metabolism, and motor behavior in rat pups; sex- and strain-dependent effects. Cerebellum 11:575-586

28. Chen YN, Wang J, Zhan J, Li SJ, He L, Shao D, Du HY (2013) Effects of Thimerosal on the neurodevelopment of premature rats. World $\mathrm{J}$ Pediatr 9:356-360

29. Ida-Eto M, Oyabus A, Ohkawara T, Tashiro Y, Narita N, Narita M (2013) Prenatal exposure to organomercury, Thimerosal, persistently impairs the serotonergic and dopaminergic systems in the rat brain: implications for association with developmental disorders. Brain Dev 35:261-264

30. Olczak M, Duszczyk M, Mierzejewski P, Meyza K, Majewska MD (2011) Persistent behavioral impairments and alterations in brain dopamine system after early postnatal administration of Thimerosal in rats. Behav Brain Res 223:107-118

31. No authors listed (1991) Haemophilus b conjugate vaccines for prevention of Haemophilus influenzae type $\mathrm{b}$ disease among infants and children two months of age and older. Recommendations of the immunization practices advisory committee (ACIP). MMWR Recomm Rep $40: 1-7$

32. Fine PE, Chen RT (1992) Confounding in studies of adverse reactions to vaccines. Am J Epidemiol 136:121-135

33. Geier MR, Geier DA (2002) The state of polio vaccination in the world: the case for continuing routine vaccination. Toxicol Mech Methods 12:221-228 